\title{
Application of Geo-Informatics to Estimate Agricultural Water Use in Samut Songkhram Province, Thailand ${ }^{+}$
}

\author{
Walaiporn Phonphan \\ Faculty of Sciences and Technology, Suan Sunandha Rajabhat University, 1 U-tong Nok Road, Dusit, \\ Bangkok 10300, Thailand; walaiporn.ph@ssru.ac.th; Tel.: +66-812-961-249 \\ + Presented at the Economy, Sustainable Development and Energy International Conference (ESDEIC), \\ Edinburgh, Scotland, UK, 25-27 June 2018.
}

Published: 30 October 2018

\begin{abstract}
Water use of human depends on daily life activities. Agriculture is the main activity of Thailand. In the present, there are the extension of agriculture, industry, residence, and community which increase water demand. It can cause a problem of water use among urban, industrial and agricultural. Most agricultural in Samut Songkhram Province, Thailand were planting crops such as pomelo, coconut and lychee, which are famous and generate a lot of income for farmers. The quality and quantity of water is an indicator for measure of the quality and yield of agricultural products. The aim of research is to estimate water use through geographic information system, and remote sensing from Landsat8 satellite. This research considers the main parameters which were; estimation of spatial rainfall runoff and quantity of evaporation, infiltration rate of the soil. To evaluate the amount of soil moisture in order to create soil moisture map for planning the utilization and management of water for agriculture. The classification land use was to investigate from Landsat8 which shown currently agricultural area. The result showed the soil moisture which distributes in each area especially the agricultural area. This information can be used by agriculturists and related organizations to plan and make the decision of growing appropriate plants according to the soil moisture for the sustainability of the agriculture.
\end{abstract}

Keywords: Geo-informatics; Geographic Information System; remote sensing; water use

\section{Introduction}

Water shortage or flooding occur from climate change and affects human life including the degradation of ecology and environment [1]. Water resources are essential for human living along with agricultural [2] that agriculture uses almost 70\% of the global freshwater [3]. Agriculture is the main activity in Thailand, so water demand from the agriculture is $90 \%$ of all demand. Water demand of the household, agricultural and industrial leads to severe pressures on water resources. It can cause some problem of water use among urban, industrial and agricultural. The water management would challenge to government to manage and simultaneously meet the needs of farmer, manufacturers, and communities. If government does not have the plan of water management or database of water demand clearly, water use conflict can be avoided and solved difficultly [4]. To maintain sustainable water resource, the database of water use in agriculture is importance data for water management. Geographic Information System (GIS) and database management system facilitates the quantification of irrigation water for regional planning and farm scale using land-use, and climate data. Remote Sensing were used to identify current land use [5]. They can be overlapped to combine and process together and used to find the solution for area base information. Moreover, they can be displayed in 
many forms to be used as the data analysis tool and a guideline for area development plan also the database for making the decision of water resource management [6]. The development of information system for water management in Thailand is in the initial stage which systematic database can improve the application in the future [7]. GIS approach to classify these areas as zones with similar hydrological characteristics suitable for irrigation and other land management practices in order to reduce the risk of salinity and waterlogging [8]. However, because of the drought problem, the amount of freshwater is not sufficient to push seawater. Moreover, water management still lacks of information link and knowledge to analyze the situation and water management such as agriculturists' water use information and water consumption of each type of plant especially vegetables and fruits. Therefore, the study of GIS to analyze water use in agricultural area of Samut Songkhram Province aims to apply GIS system to evaluate the water demand of agricultural segment which is the benefit for the government office, local organization, and people in the area.

\section{Materials and Methods}

The study water use by estimateing soil moisture and water requirements of plants. There are many parameters using to estimate soil moisture such as average weekly precipitation, weekly evaporation data, land use information, and soil series. These information will be used to study as the following sequences; Soil Moisture can be calculated by raster data or grid data analysis with Equation (1) [9]. Soil Moisture can be calculated by substitution each variable which consists of Precipitation, Evaporation, Permeability, and Runoff in the below equation;

$$
\mathrm{SM}=(\mathrm{P})-(\mathrm{R}+\mathrm{D}+\mathrm{E}),
$$

where SM = Soil Moisture (cu.m.), $\mathrm{P}=$ Precipitation (cu.m.), $\mathrm{R}=$ Runoff (cu.m.), $\mathrm{D}=$ Permeability (cu.m.), E = Evaporation (cu.m.).

By using Average Weekly Precipitation and Average Weekly Evaporation, they are used to estimate Spatial Interpolation by Kriging. The size of the grid is $30 \times 30 \mathrm{~m}$. and calculate the runoff by Soil Conservation Service-Curve Number which analyzes soil type and land use type [10]. Soil Permeability is calculated from porosity coefficient at the depth $50 \mathrm{~cm}$. [11]. Water use can be calculate from Consumptive use or Crop Evapotranspiration (ET).

\section{Results}

Studying soil moisture using GIS and water balance equation in Samut Songkhram province that found the average precipitation was 1200 million cu.m./year, and evaporation was 143 million cu.m./year. For runoff, permeability, and soil moisture were 250 million cu.m./year, 79 million cu.m./year and 98 million cu.m./year respectively. The levels of soil moisture were classified into three levels, low, medium, and high which are set as equal intervals from low equal to $0-10,00,000$, medium is 10,000,001-20,000,000, and high is 20,000,001-30,000,000. The sub districts with the highest soil moisture were Chom Pluak and Don Manora in Bang Khonthi District which equal to 28.5 million cu.m./year. The sub districts which have medium soil moisture is Yai Paeng equal to 17.6 million cu.m./year. The sub district which has the lowest soil moisture is Plai Phongphang that equal to 0.70 million cu.m./year. The study of soil moisture in Samut Songkhram using GIS found the average precipitation is 1200 million cu.m./year, the evaporation is 143 million cu.m./year, runoff, permeability and soil moisture are 250 million cu.m./year, 79 million cu.m./year, and 98 million cu.m./year respectively.

To estimate soil moisture in this study was used IDW interpolation method. The result found the sub districts which have the highest soil moisture are Chom Pluak and Don Manora in Bang Khonthi District which equal to 28.5 million cu.m./year. The sub districts which have medium soil moisture is Yai Paeng equal to 17.6 million cu.m./year. The sub district which has the lowest soil moisture is Plai Phongphang that equal to 0.70 million cu.m./year. Most of areas which have been found the soil moisture were covered by plants such as Forestry and Agriculture so the levels of soil moisture are High or Medium. For the sub districts which are the communities and buildings, they have lower soil moisture which conforms to the study of soil moisture of Yang et al. (2011) [12] that 
said the soil moisture will be controlled by land use and topography such as land, direction, location, and grade. The variance of area soil moisture will depend on topography both of depth and time which conform to the principle of United States Environmental Protection Agency that found the different cover of the topography affects the permeability, the area where covered by plant will have the better permeability than the area where covered by roads, parking, and buildings. Moreover, most of precipitation will flow according to the characteristic of the topography.

Water use for crop in agricultural can be calculate from Consumptive use or Crop Evapotranspiration (ET) equations found the average of year as 6.34 and the average of Crop Coefficient by Penman-Monteith model as 1.72 and the average of reference crop evapotranspiration as 3.81. The result of water use in agricultural were estimated from soil moisture and crop evapotranspiration using GIS technic (overlay and interpolate). The result water use in agricultural represent five levels; are high water use (Level 1) to low water use (Level 5) (Figure 1). Plai Phongphang and Wat Pradu sub district need to use the most water for agricultural.

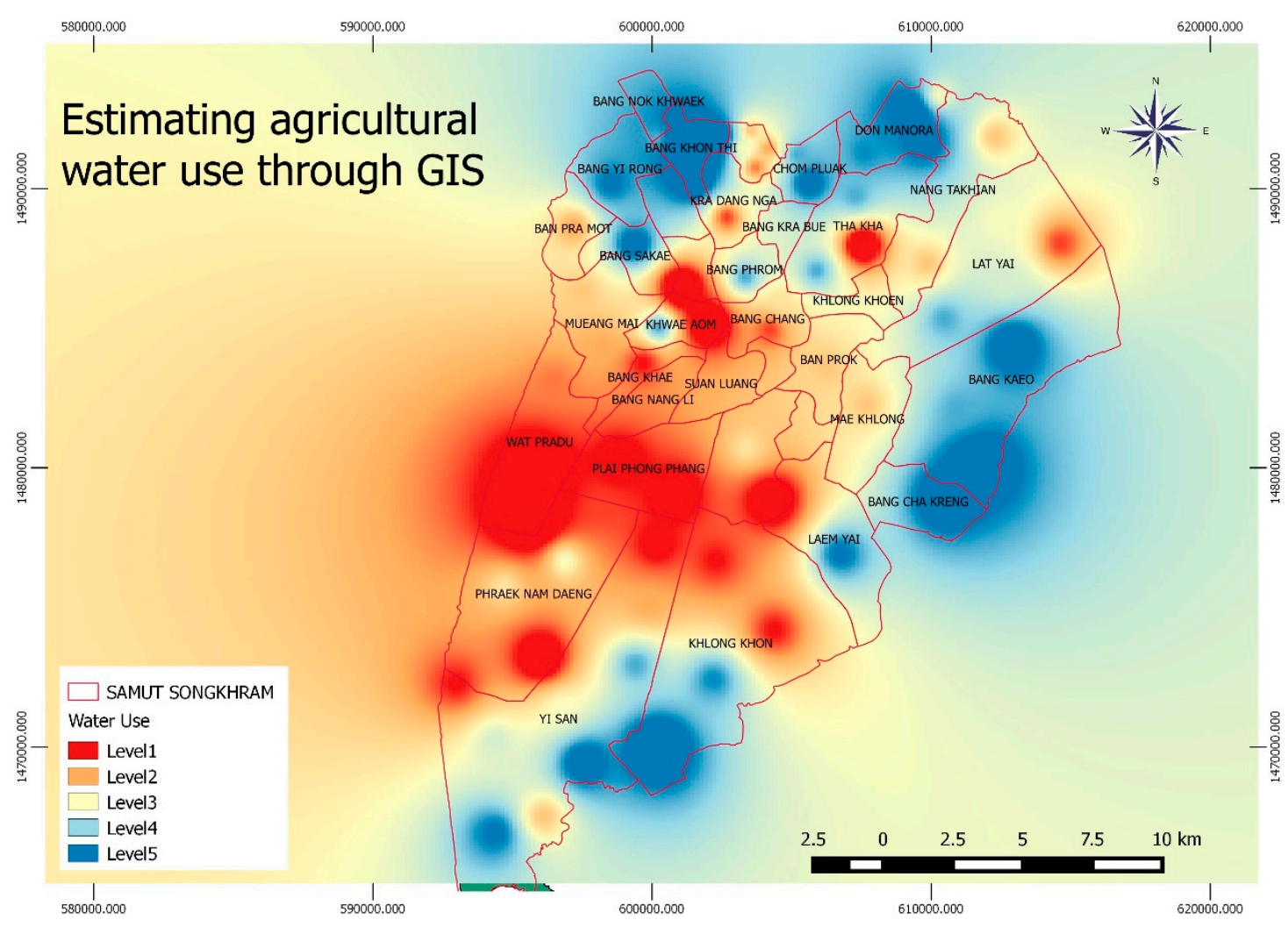

Figure 1. Water use levels in Samut Songkhram, Thailand.

\section{Conclusions}

Application of Geo-informatics to estimate water use in Samut Songkhram Province aims to apply GIS system to evaluate the water demand of agricultural segment. The result showed the soil moisture and water use which distributes in each area especially the agricultural area. This study applied water balance equation and crop evapotranspiration equation with GIS system and interpret the land use from satellite image of Landsat 8 . This information can be used by agriculturists and related organizations to plan and make the decision of growing appropriate plants according to the soil moisture for the sustainability of the agriculture. However, this research study the land use information used the satellite imagery which were medium data satellite. Therefore, there may be some change of land use and the calculated soil moisture does not reflect to the real condition. Future study should verify the soil moisture in site, in order to confirm the correction of the information for the efficiency and creditability. 
Acknowledgments: The research described in this paper is supported in part by a grant from Suan Sunandha Rajabhat University, Thailand for supporting the scholarship as a part of Budget.

\section{References}

1. Chinvanno, S. Future Climate Change in Thailand. 2004. Available online: http://startcc.iwlearn.org/doc/ Doc_thai_4.pdf.Thai (accessed on 15 June 2017).

2. Howell, T.A. Enhancing Water Use Efficiency in Irrigated Agriculture. Agron. J. 2001, 93, 281-289.

3. UNWWDR (The United Nations World Water Development Report). Water for People, Water for Life/Executive Summary; UNESCO Publishing: Paris, France, 2003; pp. 17-18.

4. Dyras, I.; Dobesch, H.; Grueter, E.; Perdigao, A.; Tveito, O.E.; Thornes, J.E.; Wel, F.; Bottai, L. The use of geographical information systems in climatology and meteorology: COST 719. Meteorol. Appl. 2005, 12, 15.

5. Paul, J.G.; Clare, H.P. Introductory Remote Sensing Digital Image Processing and Applications; Routledge: London, UK, 2000.

6. Diodato, N.; Ceccarelli, M.; Bellocchi, G. GIS-aided evaluation of evapotranspiration at ultiple spatial and temporal climate patterns using geoindicators. Ecol. Indic. 2010, 10, 1009-1016.

7. Keith, R.M. Resources Management Information System; Remote Sensing, and Modeling; CRC Press: Boca Raton, FL, USA; Taior \& Francis Group: Boca Raton, FL, USA, 2006.

8. Chen, Y.; Chen, J.; Xevi, E.; Ahmad, M.; Walker, G. GIS-based Spatial Hydrological Zoning for Sustainable Water Management of Irrigation Areas. In Proceedings of the International Congress on Environmental Modelling and Software, Ottawa, ON, USA, 5-8 July 2010.

9. Osotspa, Y.; Panichsakpatana, S.; Wongmaneeroj, A.; Thongju, C. Introduction to Soil Science; Kasetsart University: Bangkok, Thailand, 1998.

10. Wangwongwirot, N. Hydrology; King Mongkut's University of Technology Thonburi: Bangkok, Thailand, 2008.

11. Homhuan, S.; Narongrit, C. Soil Water Modeling Using Geographic Information System. J. Remote Sens. GIS Assoc. Thail. 2004, 5, 1-14.

12. Yang, Y.; Uddstrom, M.; Revell, M.; Andrews, P.; Oliver, H.; Turner, R.; Carey-Smith, T. Numerical simulations of effects of soil moisture and modification by mountains over New Zealand in summer. Mon. Weather Rev. 2011, 139, 494-510, doi:10.1175/2010MWR3324.1.

(C) 2018 by the author. Licensee MDPI, Basel, Switzerland. This article is an open access article distributed under the terms and conditions of the Creative Commons Attribution (CC BY) license (http://creativecommons.org/licenses/by/4.0/). 